\title{
DEVELOPMENT OF RECEPTIVE FACTORS ON THE PRINCIPLES OF SUSTAINABLE TOURISM DEVELOPMENT - BUDVA CASE
}

\author{
Ivo Županović ${ }^{1}$, Ana Krivokapić
}

date of paper receipt:

16.03.2020.

Review Article date of sending to review:

18.03.2020.

doi: 10.2478/eoik-2020-0002 date of review receipt:

26.03.2020.

UDK: 338.486.4(497.16Budva)

\author{
${ }^{1}$ Faculty of Business and Tourism Budva, Montenegro \\ ${ }^{2}$ Montenegro
}

\begin{abstract}
Sustainable tourism implies establishing a positive relationship and link between tourism development and environmental protection, i.e achieving a full harmony between economic and environmental interests. Tourism that is based on respect for ecological interests can ensure the constant maintenance of balance in the natural environment and tourism development. Building a private accommodation association, as one of the aspects of sustainable tourism, ensures the longterm sustainability that is needed for the destination of Budva, due to the large number of problems it encounters, starting from the gray business zone to the very poor quality private accommodation, which is higher than in basic accommodation, which should be the basis of tourism development. In view of the given problem, the subject of research of this paper is the direction in which the receptive factors in the destination of Budva should be developed, with reference to the basic and complementary accommodation units.

The aim of the research is to provide a solution for the currently unfavorable receptive situation in the destination, with special focus on diffused and integral models of private accommodation.
\end{abstract}

\section{Keywords:}

sustainable development, TBL model, carrying capacity model, diffused and integral hotels.

JEL: Z3, Z32 


\section{INTRODUCTION}

In the literature sustainable tourism is defined as a positive approach that aims to diminish the tensions which are the result of the complex interaction between the tourism industry, the visitor, the environment and the society. Sustainable tourism implies establishing a positive relationship and link between tourism development and environmental protection, i.e. achieving a full harmony between economic and environmental interests. Tourism that is based on respecting the ecological interests can ensure a constant balance in the natural environment and tourism development.

Creating a private accommodation association as one of the aspects of sustainable tourism, could ensure a long-term sustainability that is needed for the destination Budva, considering the large number of problems it encounters, starting from the gray business zone, the quality of private accommodation, the number of private accommodation in relation to basic accommodation which should be the basis of tourism development.

Considering on the given problem, the subject of research is in what direction the receptive factors in the tourist destination Budva should be developed, with reference to the basic and complementary accommodation units.

The aim of the research is to provide a solution for the currently unfavorable receptive situation in the destination.

\section{RECEPTION FACTORS}

Reception factors represent the division of accommodation capacities in one destination and are divided into the following segments:

Basic accommodation units are consisting of hotels, tourist resorts, motels and pensions Complementary accommodation units are consisting of campsites, rooms and houses for renting

\subsection{BASIC ACCOMMODATION CAPACITIES}

Hotels represent the main part of basic accommodation facilities and provide accommodation, food and drink services. Hotel signify an object operated by a caterer or a person who, under the conditions prescribed by the law for caterers, can perform this type of catering business.

Dobre (2001) points out that according to the purpose, hotels are divided into three key groups:

City hotels are located in administrative and commercial centers and are intended for business people and travelers

Tourist hotels are located in tourist resorts and are intended for accommodation of tourists

Excursion hotels are intended for excursionists and are located in a recreational areas

Hotels vary by the type of service:

Hotels that are offering bed and breakfast

Hotels that are offering bed and full board service

Other accommodation facilities that provide accommodation and meals are as follows:

Motels are located next to the main roads and provide accommodation and meals

Tourist settlements are catering facilities that provide accommodation and a food preparation service and are mostly built as more buildings in one space

Pensions are located in tourist places and provide accommodation and meals for a longer period of time

Resorts are facilities that are intended for rest and recreation and provide accommodation and food services

Hostels are offering an affordable price and are intended for younger people 


\subsection{COMPLEMENTARY ACCOMMODATION CAPACITIES}

Complementary capacities strongly influence the volatility of the total destination offer.

The complementary accommodation facilities include the following segments:

Private accommodation is a term that indicates accommodation capacities owned by individuals. Private accommodation includes accommodation units such as apartments, rooms, holiday homes...

Camps represent tourist settlements where tourists can rent campsites with accompanying amenities In order to develop a destination in the direction of the tourist destination, it is necessary to have a smaller number of complementary accommodation capacities, and a larger number of basic accommodation capacities.

\section{SUSTAINABLE TOURISM}

Nowadays, many tourist destinations are developing rapidly, wanting to achieve only economic benefits, forgetting about natural and cultural resources, unwittingly destroying and polluting it. For this reason, it is necessary to develop tourism based on sustainability. The contribution of tourism to sustainable development is also great, in terms of the growth of economic factors and raising the standard of living.

Swarbroke (1999) defined as a shape of tourism which must fulfills needs of tourists, tourism industry and host population without compromising the ability of future generations to achieve their own needs for a normal daily life functioning.

Sustainable tourism needs to make a balance between economic, natural and socio-cultural factors in one destination. The World Tourism Organization (UNWTO) believes that sustainable development can be applied to all forms of tourism and in all tourist destinations.

Cernat and Gourdon (2007) take into account similar factors, such as tourism-related factors : economic sustainability (tourism assets, tourism activity, linkages and leakage effects), influence of basic infrastructure and environmental and social sustainability..

UNWTO (2013) pointed out that sustainable tourism should not be treated as a particular element of tourism, as a set of niche products, than a condition of the tourism sector as a whole, which should work to become more sustainable.

Authors of Heland project, University of Malta (2015), quality assured through sustainable tourism clarifies as valuable experience for visitors, in the context of improving quality of daily life of local population and taking into consideration importance of natural resources.

\subsection{TRIPLE BOTTOM LINE AS A SUPPORT FOR THE DEVELOPMENT OF SUSTAINABLE TOURISM}

Jegdić (2011) claims that the TBL approach is a consideration of the environmental, economic and social consequences for companies and their stakeholders (Figure 2). By using TBL approach we can enable efficiency and improvement of relations among the stakeholders. With this approach, we identify the roles of internal stakeholders, governments and business associations.

The necessity of integrating TBL approach into the process of strategic planning of tourist organizations is emphasized, as an asset that contributes to the promotion of sustainability in tourism business. Outcomes include transparency and accountability which are necessary to demonstrate to the stakeholders and government, that represent a socially responsible business of a tourist entity [Jegdić, 2011].

The triple bottom line measures the success of an organization or society that can be economic, environmental and social. The TBL model enables the calculation of costs in given segments, making business decisions, planning and reporting, where all the responsibility is based on stakeholders. 
By applying a TBL model in one organization, worker behavior and the selection of indicators are harmonized, the adoption of the appropriate system for TBL calculation and monitoring of results, as well as dealing with the costs of TBL implementation. The development of TBL strategies, activities and indicators includes cooperation among the stakeholders. Companies must understand, identify and evaluate how their activity affects the stakeholders, what are the main interests / issues of the stakeholders and ensure that their positive initiatives are recognized.

\subsection{THE CARRYING CAPACITY OF A TOURIST DESTINATION}

UNWTO defines the carrying capacity of a tourist destination as the maximum number of people who can visit a tourist destination in the same period without causing harmful consequences for the physical, economic and socio-cultural environment and without unacceptable decrease in the quality of tourist satisfaction. Carrying capacity is crucial for environmental protection and sustainable development. There are four types of carrying capacity:

Physical carrying capacity is characterized by the number of inhabitants and visitors in one place, i.e. the number of tourists who can be accommodated in one area, the acceptable level of concentration at the key locations, utilization intensity of capacities, and the traffic infrastructure

The environmental carrying capacity refers to the number of tourists who can stay in the destination, while at the same time there is no negative impact on the environment, then the level of pollution in a tourist destination where ecological systems are maintained without causing more damage, preservation of cultural and historical objects, acceptable water and air pollution, noise...

Cultural carrying capacity means the level of tolerance of the local residents / tourists in relation to the presence of other tourists, i.e. not endangering of the cultural identity of the local community Economic carrying capacity refers to the number of tourists who can stay in the destination, without a negative impact on the economy of the local population, i.e. the level of tourism that provides economic benefits, without some negative effects

Carrying capacity refers to the number of tourists who, under certain conditions, can stay in a destination without undesirable consequences for the environment and the quality of visitor experience, and the satisfaction of the local community [Jegdić, 2011].

Pasinović (2006) points out the following factors which determine the maximum of carrying capacity:

Local factors imply destination ability to accept a certain number of tourists, the impact of tourists on destination culture, economic benefits from tourism, political support /obstruction of tourism development, competitiveness of destination in relation to natural and tourist resources

External factors characterize the social side of the tourist - difference between the cultural and social environment of the local population and tourists will cause changes in the environment

Other factors, such as planning, management, standards and parameters that certainly have an impact on the limit of carrying capacity

As each destination aims to develop tourism in a sustainable way, it is necessary to stop the destination's exposure to some serious changes.

\subsection{MAXIMUM RECEPTION CAPACITY OF THE DESTINATION}

Accelerated growth and development of tourism in the destination Budva had a negative effect on natural resources by excessive and unplanned building of complementary accommodation capacities, what is an indication of the unsustainable development of the destination. The maximum accommodation capacity of the destination Budva is shown in the following examples:

1. Seasonal concentration of tourists 
Table 1. Seasonal concentration of tourists 2016.

\begin{tabular}{|c|c|c|}
\hline Months & Arrivals & Overnight stays \\
\hline January & $(4.557)$ & $(13.628)$ \\
\hline February & $(4.583)$ & $(11.010)$ \\
\hline March & $(8.081)$ & $(18.054)$ \\
\hline April & $(23.970)$ & $(62.486)$ \\
\hline May & $(44.461)$ & $(182.567)$ \\
\hline Jun & $(83.577)$ & $(539.141)$ \\
\hline Jul & $(203.525)$ & $(1.391 .651)$ \\
\hline August & $(265.194)$ & $(1.839 .561)$ \\
\hline September & $(127.038)$ & $(824.870)$ \\
\hline October & $(25.900)$ & $(88.327)$ \\
\hline November & $(7.331)$ & $(18.810)$ \\
\hline December & $(8.254)$ & $(14.812)$ \\
\hline TOTAL & $(806.471)$ & $(5.004 .917)$ \\
\hline
\end{tabular}

Source: Monstat.

According to official data from the Monstat in 2016., 806,471 tourist arrivals and 5,004,917 overnight stays were recorded. In the period of the main season in June, July, August and September, 679,334 arrivals were realized, which is $84.23 \%$ of the total amount of arrivals, and the number of overnight stays is $4,595,223$, which is $92 \%$ of the total number of overnight stays.

From the above data we can conclude that the seasonal concentration of tourists in the months of the main season exceeded all the limits of endurance, so that is an alarming situation for the destination, and urgent measures must be taken to solve this problem.

2. Number of tourists and parking capacity

Since the destination does not have enough developed air traffic and connectivity, most of the tourists come by a car, which causes enormous crowds in traffic, as well as the lack of parking places. The following table shows parking places in Budva.

Table 2. Location and number of parking places

\begin{tabular}{|c|c|}
\hline Location of parking space & Number of parking spaces \\
\hline Jat & $(\mathbf{5 5})$ \\
\hline Zeta movie & $(\mathbf{8 5})$ \\
\hline Exponat & $(\mathbf{1 0 5})$ \\
\hline Kindergarten & $(\mathbf{2 5})$ \\
\hline The post office & $(\mathbf{8 0})$ \\
\hline Municipality & $(\mathbf{7 5 )}$ \\
\hline Slovenian beach & $\mathbf{( 3 5 0 )}$ \\
\hline Garage TQ Center & $(\mathbf{2 3 0})$ \\
\hline Mediterranean street & $(\mathbf{5 5})$ \\
\hline South Boulevard & $(\mathbf{8 0})$ \\
\hline Hotel Palas & $(\mathbf{1 5 0})$ \\
\hline Hotel Oliva & $(\mathbf{2 2 0})$ \\
\hline The post office Petrovac & $(\mathbf{6 0})$ \\
\hline TOTAL & $(\mathbf{1 . 5 7 0})$ \\
\hline
\end{tabular}

Source: Knežević, A. (2017), Master thesis - Maximum reception capacity as a key factor of sustainability of the tourist destination, Budva. 
In August 2016. the number of tourists who visited Budva is 265,194 , that is 8,839 tourists daily. If every fourth tourist comes by car, it is required demand for 2,210 parking spaces. According to Knežević (2017) the total number of parking places in the Municipality of Budva is 1,570 places, what is $29 \%$ less than the required parking places. Considering the demand of the local population for parking places, a significant parking deficit is evident.

3. Relation of accommodation capacities and local population

The ratio of the number of beds and the number of inhabitants seems even more unfavorable. Municipality of Budva has more beds for rent in relation to the number of inhabitants. Destinations that develop tourism should have a ratio of the number of beds 1.5: 1 in relation to the number of inhabitants.

The number of registered accommodation capacities in the Municipality of Budva in 2016. is 58.213 , while the number of inhabitants is 20.523 . By correlating these two amounts, we get a ratio of 2.84:1, which is a higher than it should be and represents an unsustainable development.

\section{MODERN MODELS OF ACCOMMODATION MANAGEMENT}

The integration of private accommodation into diffused or integral hotels is one of the key activities and is carried out with the aim of creating a new tourist product in the destination, development and improvement of the quality of accommodation units, joint market advancement and market recognition, increasing the number of employees and strengthening competitiveness.

The following table shows the differences between diffused / integral hotels and complementary accommodation.

Table 3. Differences between diffused / integral hotel and private accommodation

\begin{tabular}{|l|l|}
\hline DIFFUSED OR INTEGRAL HOTEL & PRIVATE ACCOMMODATION \\
\hline Business throughout the year & Seasonal business \\
\hline Reception & Reception of guests on the "home threshold" \\
\hline Engagement about the free time of guests & $\begin{array}{l}\text { Guests get everything they need, without } \\
\text { additional engagement on activities }\end{array}$ \\
\hline Authenticity of accommodation & $\begin{array}{l}\text { The appearance of the accommodation } \\
\text { depends on the owner's style }\end{array}$ \\
\hline $\begin{array}{l}\text { Encouraging the local population to engage in } \\
\text { tourism }\end{array}$ & Unhealthy competition \\
\hline $\begin{array}{l}\text { Impact on the development of the } \\
\text { environment }\end{array}$ & Own development \\
\hline "Selling" the whole destination & Sells its services and products \\
Source: https://www.dura.hr/user_files/dura/TZ\%20-\%20DIFUZNI\%20HOTELI.pdf
\end{tabular}

The development of diffused / integral hotels influences the entire community and produces economic effects on the economy. Therefore, in order to deal with the quality of the already existing private accommodation in Budva, as well as accommodation in the gray business zone, it is necessary to form the association of accommodation owners and organise diffuse / integral hotels within the settlement.

The following table shows the difference between integral and diffused hotels. 
Table 4. The difference between diffused and integral hotels

\begin{tabular}{|c|c|c|}
\hline & DIFFUSED HOTELS & INTEGRAL HOTELS \\
\hline SERVICES & $\begin{array}{l}\text { - Accommodation } \\
\text { - The breakfast } \\
\text { - Other catering services }\end{array}$ & $\begin{array}{l}\text { - Accommodation } \\
\text { - The breakfast } \\
\text { - Other catering services }\end{array}$ \\
\hline DESCRIPTION & $\begin{array}{l}\text { - } 3 \text { and more buildings in one settlement } \\
\text { - Located in old, traditional historical, } \\
\text { rural - urban } \\
\text { structures, decorated and furnished in a } \\
\text { traditional way }\end{array}$ & $\begin{array}{l}\text { - } 3 \text { and more buildings / facilities in one } \\
\text { settlement, previously categorized and / } \\
\text { or classified }\end{array}$ \\
\hline COMMON FEATURES & $\begin{array}{l}\text { - Reception hall with reception desk } \\
\text { - A common room for a stay } \\
\text { - Accommodation units } \\
\text { - A common sanitary facility } \\
\text { - Other tourist catering facilities }\end{array}$ & $\begin{array}{l}\text { - Reception hall with reception } \\
\text { - Shared living room } \\
\text { - Accommodation facilities in at least } 2 \\
\text { separate buildings } \\
\text { - A common sanitary facility } \\
\text { - Other tourist catering facilities }\end{array}$ \\
\hline $\begin{array}{l}\text { ACCOMMODATION } \\
\text { UNITS }\end{array}$ & $\begin{array}{l}\text { - Rooms } \\
\text { - Hotel suites } \\
\text { - Family rooms } \\
\text { - Studio apartments } \\
\text { - Apartments }\end{array}$ & $\begin{array}{l}\text { - Rooms } \\
\text { - Apartments } \\
\text { - Condominium apartments } \\
\text { - Houses }\end{array}$ \\
\hline
\end{tabular}

Source: https://www.dura.hr/user_files/dura/TZ\%20-\%20DIFUZNI\%20HOTELI.pdf

The main difference between the diffused and the integral hotels is that diffused hotels are located in traditional-historical buildings, furnished in a traditional manner.

According to the data of the Secretariat for ecomony Budva, the following graph 1 shows the total private accommodation in Budva

Graph 1. Private accommodation capacities in tourist destination Budva

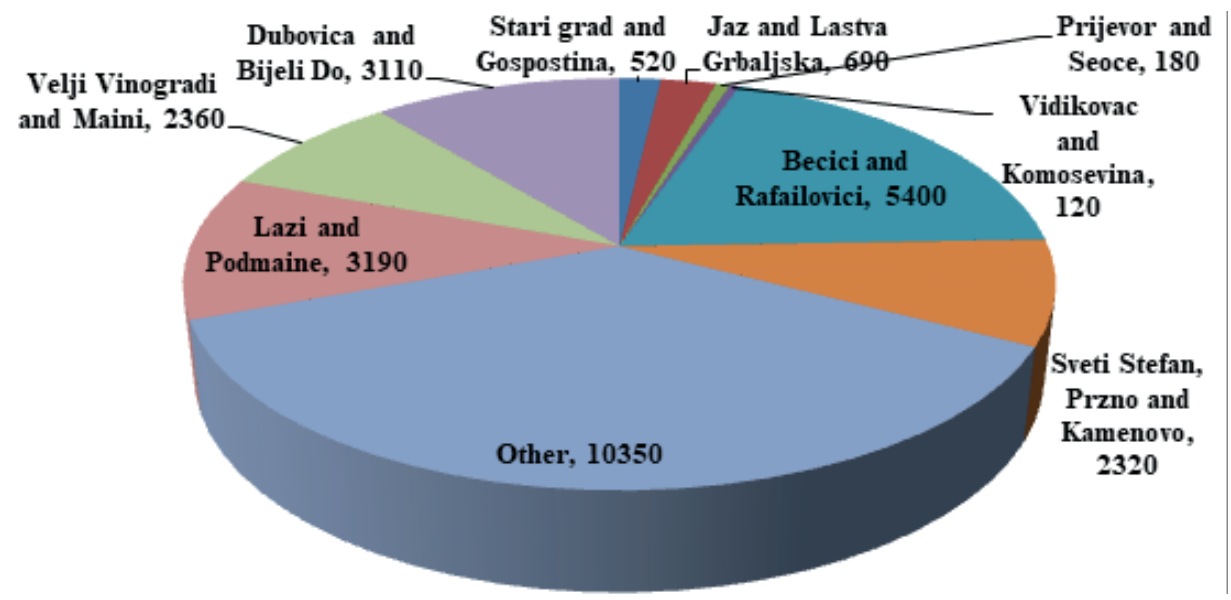

Source: Authors's own research.

After completing the offer of accommodation capacities in private accommodation, European Union (2013) claims that it is necessary to make a proposal for conceiving diffused and integral hotels, which should contain the following:

Joint management

Presence of common rooms for hotel guests

Offer of hotel services (reception, breakfast, cleaning ...) and logistics for guests

Host community presence - guests integration into the socio-cultural environment of the destination Reasonable distance between guest units and common rooms 


\subsection{THE MODEL OF NETWORKING PRIVATE ACCOMMODATION IN DIFFUSED HOTELS}

Dragicevic and Letunic (2015) stated that the crucial advantage of diffused hotels is that the components of the tourist product are arranged in different properties located in the same town. Furthermore, the diffused hotel must be in predominantly urban, historical, but also rural-urban structures and buildings, arranged and equipped in a traditional manner. It is a functional whole in the area of a settlement consisting of three or more functionally connected buildings fitted into the local environment and lifestyle.

The following picture shows an example of the creating a diffused hotel in the settlements Old Town ( 280 beds) and Gospoština ( 240 beds) that have a total of 520 beds for rent.

Figure 1. Google map view: An example of a diffused hotel model in the tourist destination Budva

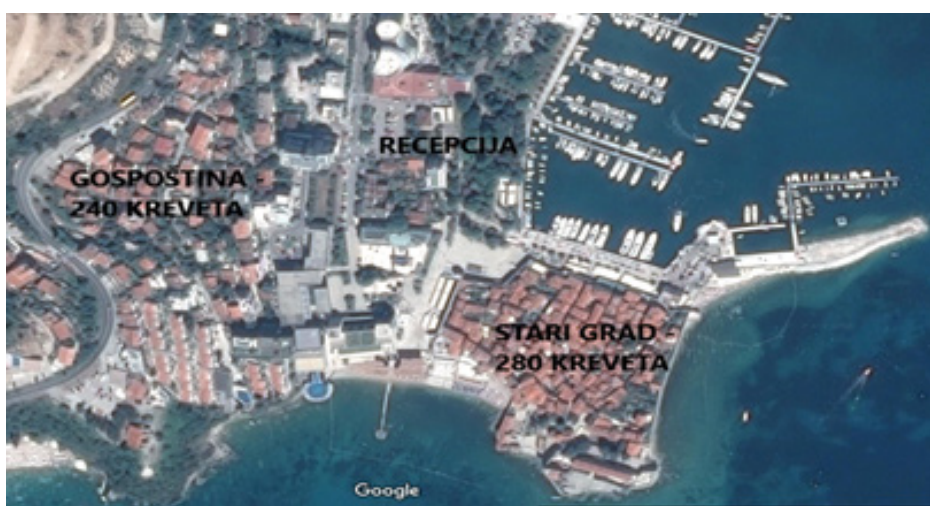

Source: Authors's own research.

The settlements Old Town and Gospoština are the only ones that have old traditional-historical buildings in Budva, which are included in the concept of diffused hotels, and because of the smallest number of accommodation capacities and proximity, their integration is recommended. In order to meet the technical conditions, the diffused hotel must have the following:

The architectural and artistic value of the historic core of the city and the value of the natural and cultural resources of the area, and the attractive environment (the sea, other natural beauties and cultural sights), which these settlements already possess

Existence of a central building of a diffused hotel, where can be located a reception, a common room for guests stay, and other technical facilities, so it can be in the former building of Jat airline Creating the model of diffused hotels can bring the following benefits:

Adequate and affordable adaptable capacities in the off-peak season, which will enable the extension of season and the possibility to offer tourists a longer stay in cultural and entertainment attractions Joint market presence, which will reduce the costs of promotion and distribution

\subsection{THE MODEL OF NETWORKING PRIVATE ACCOMMODATION IN INTEGRAL HOTELS}

Galičić (2017) points out that an integral hotel is an object where the caterer provides accommodation services and breakfast in shared facilities, in catering facilities and / or facilities of other caterers and / or renters, who joined together. An integral hotel is a functional unit in three or more buildings or parts of buildings in one settlement. Buildings or parts of the hotel buildings can be distributed throughout the settlement between objects of other purposes.

Catering facilities in which catering services are provided can be separated by public or shared surfaces. 
For all other areas in Budva, it is recommended to organise integral hotels, because it is mainly about accommodation in residential buildings and houses:
Prijevor and Seoce
Bečići and Rafailovići
Velji Vinogradi and Maine
Lazi and Podmaine
Jaz and Lastva
Vidikovac and Komoševina
Sveti Stefan, Pržno and Kamenovo

The following picture shows the example of an integral hotel in the settlements Bečići (2500 beds) and Rafailovići (2900 beds), which have the largest number of beds for rent, in total 5400 beds.

Figure 2. Google map view: An example of an integral hotel model in the tourist destination Budva

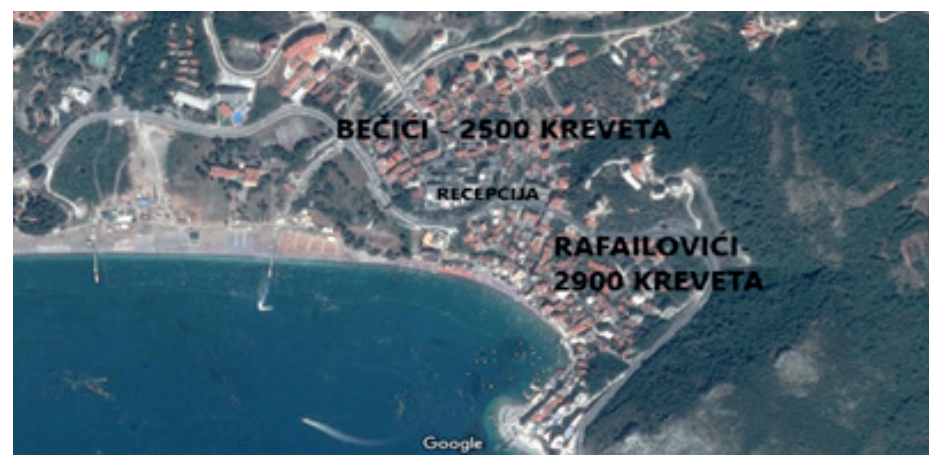

Source: Authors's own research.

An integral hotel in the area of Bečići and Rafailovići must have the following items fulfilled:

Reception hall with reception and a common room for stay, which is recommended to be on Bečići boulevard

Breakfast can be arranged at nearby cafes and restaurants

In case of a longer distance, it is necessary to arrange transportation for guests, from reception to accommodation

Maintenance of the environment and buildings

Providing other services to the guests

Pre-categorized accommodation that depends on the target tourist groups

\section{CONCLUSION}

The global expansion of massive tourism causes pollution and saturation in tourist destinations, and damages heritage such as culture, tradition, customs and lifestyle. The center of interest in current tourism is the prevention and modification of these phenomenons. Modern tourism requires organizational approach to the problems, where the theory of sustainable development plays an important role.

Networking accommodation capacities in the hotel industry, especially if we are talking about integral and diffused hotels, i.e. the improvement of the complementary part of the accommodation also means overcoming gray business zone in the tourist destination Budva. Interdependent companies must work together to achieve more successful goals, such as market recognition and extension of the tourist season, which is one of the biggest problems in the destination.

Implementation of this strategy is a long-term process that continuously manages changes in the organizational structure of accommodation capacities. It is possible to create a more balanced 
occupancy and better cooperation with tour operators, who are an important aspect for filling accommodation capacities. By networking the accommodation offer, a large number of efficient strategic benefits can be provided, so it is an excellent method for differentiating the offer from competitive strategies and models.

Relying on the strategy of Croatian tourism development, where the strategy of diffused and integral hotels has already been revived, as the best solution for overcoming the problem of a large number of complementary capacities in relation to the basic ones, I consider that all destinations within Montenegro that have problems with complementary accommodation, need to turn to this long-term sustainable strategy.

More than half of the accommodation capacities in Montenegro belongs to this category, so it is a red alarm to undertake activities for merging and shaping such a product that would satisfy the needs of the local population in terms of higher employment, as well as meeting the needs of the target groups in terms of quality of accommodation, and on the other hand it would close the area for illegal construction and accommodation owners.

\section{REFERENCES}

Cernat L., Gourdon J.,(2007), Is the concept of sustainable tourism sustainable, United Nations, New York and Geneva.

Dobre, R. (2001), Economics and organization of catering companies, Higher School of Tourism, Šibenik.

Dubrovnik Development Agency, (http://www.dura.hr/)

Dragicevic M., Letunic S., (2015), Diffuse hotels in the function of creating augmented agricultural households tourist offer based on innovations, Procedia Economics and Finance 32, Elseiver B.V. European Union-European Regional Development Fund (2013), Diffused hotel a model to develop tourism through innovation and tradition, Cultural Site and tourism development of European strategies.

Galičić, V. (2017), Business of the hotel accommodation department, Faculty of Tourism and Hospitality Management, Opatija.

Heland project, University of Malta, (2015), Sustainable tourism management, George Cassar, Sliema, Malta.

Internal documentation of the Secretariat for Economy (2017), Budva.

Jegdić, V. (2011), Tourism and Sustainable Development, Faculty of Sport and Tourism, Novi Sad. Knežević, A. (2017), Master thesis - Maximum reception capacity as a key factor of sustainability of the tourist destination, Budva.

Monstat, (http://www.monstat.org/)

Pasinović, M. (2006), Management of Natural and Cultural Resources, University Mediteran, Bar. Secretariat for Economy (2017), Internal documentation, Budva.

Swarbroke J.,(1999), Sustainable tourism management, CABI publishing, London.

UNWTO (2013), Sustainable Tourism for Development Guidebook, Enhancing capacities for Sustainable Tourism for development in developing countries, Madrid. 